\title{
Sources of Polycyclic Aromatic Hydrocarbons in Street Dust from the Chang-Zhu-Tan Region, Hunan, China
}

\author{
Yongzhen Long ${ }^{1 *}$, Guoxiang $\mathrm{Chi}^{2}$, Hairuo Qing ${ }^{2}$, Tagen Dai ${ }^{1}$, Qianhong Wu ${ }^{1}$ \\ ${ }^{1}$ Educational Key Laboratory of Non-Ferrous Metal Materials Science and Engineering, Central South University, Changsha, China; \\ ${ }^{2}$ Department of Geology, University of Regina, Regina, Canada. \\ E-mail: *Jilllongyz@163.com
}

Received September $15^{\text {th }}, 2011$; revised October $16^{\text {th }}, 2011$; accepted November $18^{\text {th }}, 2011$.

\begin{abstract}
Street dusts collected from 20 sites as well as three special dust samples collected from chimney of coal-fired plant, smelter and refinery of nonferrous metals and automobile exhaust, respectively, in the Chang-Zhu-Tan (Changsha, Zhuzhou and Xiangtan) urban region, Hunan, China, in May to August 2009, were investigated for sources of polycylic aromatic hydrocarbons (PAHs). The $\Sigma P A H s 16$ levels were in the range of $3515-24488 \mathrm{ng} / \mathrm{g}$, with a mean of $8760 \mathrm{ng} / \mathrm{g}$. The sources of PAH inputs to street dusts were determined by isomer ratios, principal components analysis and REE geochemical analysis. The isomer ratios suggested a rather uniform mixture of coal combustion and petroleum PAH sources. Factor analysis indicated that the main sources of 16 PAHs were coal combustion/vehicle exhaust and coking/ petroleum. Rare earth elements (REE) and Factor score analysis further indicated the possible dust sources were from background soil, coal or coking combustion, nonferrous metal factories, traffic exhaust.
\end{abstract}

Keywords: Street Dust, Polycclic Aromatic Hydrocarbons, Rare Earth Element, Sources of Pollution

\section{Introduction}

The number and diversity of contaminants in our urban environment have significantly increased in recent years [1]. Current evaluations show that increases of urban dust load, alone or in combination with other pollutants, lead to different health effects [2]. Near-surface atmospheric dust was a mixture of particles of the atmosphere and surface dust of the ground which provided important information for pollution management. These substances can be absorbed or taken in by the body through the respiratory tract and skin, and digested, absorbed, and accumulated in the human body. These harmful substances can also be washed out by precipitated water into the soil and rivers leading to direct pollution of the urban environment [3]. The distribution and concentration of polycyclic aromatic hydrocarbons (PAHs) coated to the dust were paid special attention because of their carcinogenicity, mutagenicity and toxicity, and consequently had been put into the list of priority monitoring pollutants by the United States Environment Protection Agency (USEPA) $[4,5]$. Monitoring and protecting the atmosphere against the adverse effects of persistent organic pollutants (POPs) were also the main aims of the European Monitoring and Evaluation Programme (EMEP) on long-range transmission of air pollutants [6]. The widespread distributions of PAHs in dust had been intensively investigated [7-9], especially in industrialized countries. PAHs in the environment largely are a product of the incomplete combustion of petroleum, oil, coal, and wood [10]. Sources in the urban environment include industrial emissions and wastes, power plants, wood and coal, home heating with fuel oil, vehicles, mineral/crude oil extraction and petroleum refining processes [11] as well as pavement sealants, also known as sealcoat [12].The recognition of these anthropogenic sources was very important for improving city management. In this respect, PAH isomer pair ratios had been widely used to elucidate the possible sources. The ratios between low and high molecular weight PAHs [9] and those of specific compounds, such as Flu/(Flu + Pyr), $\mathrm{BaA} /(\mathrm{BaA}+$ Chry $)$, Flu/Pyr and BaA/Chry have been proposed as valuable source indicators [13]. Factor analysis has also been used to identify the sources of particulate matter in the atmosphere [14]. The rare earth elements (REEs) are well known for their unique, chemically 
coherent behavior which makes them ideal geochemical tracers for many geologic processes [15]. Recently, Gabrielli used rare earth elements to tracer the continental dust origin in EPICA Dome $\mathrm{C}$ ice during glacial and interglacial periods [16]. Here, we present REE to trace the sources of street dust as well as PAH isomer pair ratios and Factor Analysis to trace the sources of PAHs in dust. The different methods can be integrated in order to better understand the PAH pollu- tion sources in urban areas [9]. The Chang-Zhu-Tan region, one of the pioneers of urban agglomeration in China as well as the hub of communication in the middle and south China, includes the cities of Changsha, Zhuzhou and Xiangtan, where lots of interstate highways cross these metropolitan areas. The ChangZhu-Tan region covers an area of approximate 28,088 $\mathrm{km}^{2}$, with its inhabitants population swelling from 12.76 millions in 2005 to 13.10 millions in 2008 [17]. Changsha is the capital and the largest city of Hunan Province, as well as the centre of politics, economy, technology, culture and transportation in Hunan province. Zhuzhou is the second largest city and the largest industry city in Hunan province. Xiangtan is the third largest city and an important industry and transportation center in Hunan province. In the mean time, Hunan is well known for its richness of mineral resources and has the name of "the country of nonferrous metals". Hunan is the number one producer of lead and zinc and among the top three producers of ten nonferrous metals in China [18]. Major nonferrous metals industries are distributed in this region. The major sources of combustion-related organic compounds in this region were coal, crude oil and coking, with annual consumption of 11.79 million tons of coal in 2000 [19], 3.83 million tons of crude oil and 1.93 million tons coking in 2007 [17], followed by natural gas, kerosene, gasoline, liquefied petroleum gas and other fuels, with annual consumption of 41.76, 28.66, 19.83 and 15 million tons, respectively [17]. Coal is largely used for thermal power plants in Zhuzhou and Xiangtan, while coking is largely used for Xiangtan iron and steel works, Zhuzhou Smelter and Refinery of nonferrous metals, Zhicheng Chemical plant and other plants. All sorts of plants with their numerous coal or coking ovens were distributed in this region, especially in Zhuzhou and Xiangtan industrial areas. However, in most case, no distinct borderline existed between industrial areas and other function areas, such as residential and office areas. In the recent years, with the accelerating integration process of Chang-Zhu-Tan region, the concomitant increase in traffic circulation (the annual rate of vehicle numbers increase has maintained $15.5 \%$ in the recent 10 years [20], industry productions and population density have adversely impacted the air quality in many quarters of this region. Large amount of data on concentration levels for suspended particulate Matter $(\mathrm{SPM}), \mathrm{NO}_{\mathrm{x}}, \mathrm{SO}_{2}$ and $\mathrm{CO}$ are available for these urban areas, which have been found to be consistently much higher than the permissible limit. As things stand, air pollution in this region is largely due to industries and vehicles have also been targeted for tacking air pollution. However, not much attention has been paid to measurements of toxic and mutagenic compounds such as PAHs which affect human health. Relatively little information about these compounds in the dust is available. Therefore, measurements of their levels in the urban dust are of great interest.

This paper reports the sources of PAHs in street dust of the Chang-Zhu-Tan area (longitude from $110^{\circ} 53^{\prime}$ to $114^{\circ} 15^{\prime}$ and latitude from $26^{\circ} 3^{\prime}$ to $28^{\circ} 40^{\prime}$ ). The concentrations of PAHs were analyzed and their spatial variations were evaluated. The possible sources of PAH contamination were studied using the methods of isomer ratios, principal components analysis and REE analyses. The purpose of the study is to evaluate the current situation of PAHs pollution in this area and their potential controlling factors and to provide a reference for regulatory action to improve environmental quality in this region.

\section{Materials and Methods}

\subsection{Sample Collection Method}

Sampling sites were selected in the centre of the three cities, based on different anthropogenic activities such as vehicular traffic density and industrial, commercial as well as other local activities. Sets of stainless steel plates (area $60 \times 40 \mathrm{~cm}^{2}$, height $5 \mathrm{~cm}$, flat bottom) for collecting bulk deposition (dry and wet depositions mixed together) were placed at eight sites in Changsha, six sites in Xiangtan and Zhuzhou respectively. Sampling was conducted from May 15 to August 5, 2009, with sampling sites described in Table 1, while the height of all sampling sites to the ground was about $1.5 \mathrm{~m}$. Besides, the special dust samples ZDD, ZYD and CWG were taken from the chimney of Xiangtan coal-fired power plant, the chimney of Zhuzhou Smelter and Refinery of Nonferrous Metals and automobile exhaust, respectively. Dust particles were wiped off from the bottom of plates with a brush, dried in a desiccator for 48 hours, and then ground using a mortar and pestle and sieved (200 mesh). The samples were refrigerated $\left(4^{\circ} \mathrm{C}\right)$ during transport to the laboratory, where they were stored at $-20^{\circ} \mathrm{C}$ until analyzed.

\subsection{PAHs Analysis}

A PAH analysis procedure was developed after modifycations of several PAH analysis methods in the literature 
Table 1. Sample sites and environmental data for street dust in Chang-Zhu-Tan region.

\begin{tabular}{|c|c|c|c|}
\hline Number & Sample ID & Sample site & Representative environment \\
\hline 1 & $\mathrm{C} 1$ & Jinfan district & Densely populated with residential house \\
\hline 2 & $\mathrm{C} 2$ & Wuyi Square & The centre of Commercial and residential in Changsha city \\
\hline 3 & $\mathrm{C} 3$ & Changsha Evening Paper & Commercial area, with heavy traffic intersection \\
\hline 4 & $\mathrm{C} 4$ & Dongtun Ferry & Traffic area near Xiangjiang River \\
\hline 5 & $\mathrm{C} 5$ & Yanzi Nest & Residential area \\
\hline 6 & C6 & Changsha Southern Bus Station & Area of heavy traffic \\
\hline 7 & $\mathrm{C} 7$ & Changsha Municipal Government & Office area with higher percentage of greenery coverage \\
\hline 8 & $\mathrm{C} 8$ & Changsha Western Bus Station & Traffic area, under the Yulu Mountain \\
\hline 9 & $\mathrm{Z} 1$ & Baoting village & Residential area \\
\hline 10 & $\mathrm{Z} 2$ & Zhicheng Chemical plant & Industrial region of chemical plants \\
\hline 11 & $\mathrm{Z} 3$ & Luojiachong & Residential area, between two high ways \\
\hline 12 & $\mathrm{Z} 4$ & Qinyun village & Restaurant near one main road \\
\hline 13 & $\mathrm{Z} 5$ & Zhuzhou Municipal Government & officer area and shopping center, near one main road \\
\hline 14 & Z6 & Geological Survey of Zhuzhou Institute & Office area \\
\hline 15 & $\mathrm{X} 1$ & Bantangpu & Industry area, near one main road \\
\hline 16 & $\mathrm{X} 2$ & Jianshe Road & Residential area \\
\hline 17 & $\mathrm{X} 3$ & Xiangtan Eastern Bus Station & Area of traffic \\
\hline 18 & $\mathrm{X} 4$ & Yuetang & Industrial area, near one main road. \\
\hline 19 & $\mathrm{X} 5$ & Xiangtan coal-fired power plant & Industrial area \\
\hline 20 & $\mathrm{X} 6$ & Xiangtan Municipal Government & Office area, at the west of Xiangtan coal-fired power plant \\
\hline 21 & ZDD & Xiangtan & the chimney of Xiangtan coal-fired power plant \\
\hline 22 & ZYD & Zhuzhou & the chimney of Zhuzhou Smelter and Refinery of Nonferrous Metals \\
\hline 23 & CWG & Changsha & automobile exhaust \\
\hline
\end{tabular}

[8]. Analytical procedure, samples extraction, separation, cleanup and concentrating were carried out in the Key Laboratory of Organic in Guangzhou Institute of Geochemistry, Chinese Academy of Sciences. Dust sample (5 g dry weight) was weighed into a Soxhelt extractor, while $200 \mathrm{~mL}$ dichloromethane, $2 \mathrm{~g}$ activated $\mathrm{Cu}$ mesh and surrogate standards were added into a $250-\mathrm{mL}$ flask. Activated $\mathrm{Cu}$ was added for desulphurization. A mixture of deuterated PAH surrogate standards (NAP-d8, ACEd10, PHE-d10, CHR-d12) was added into each sample prior to extraction. Then the sample was Soxhlet-extracted continuously for $48 \mathrm{~h}$ at a temperature of $46^{\circ} \mathrm{C}$. The extract for each sample was concentrated and solvent-exchanged to hexane, and further purified using 1:2 aluminum/silica column chromatography. The first fraction containing aliphatic hydrocarbons was eluted with $15 \mathrm{ml} \mathrm{n}$-hexane. The second fraction containing PAHs and organochlorine pesticides (OCPs) was eluted with 70 $\mathrm{ml}$ of a mixture dichloromethane and $\mathrm{n}$-hexane $(\mathrm{V}: \mathrm{V}=$ 40:60). The third fraction containing PAEs (phthalate esters) was eluted with $40 \mathrm{ml}$ of a mixture acetone and nhexane $(\mathrm{V}: \mathrm{V}=20: 80)$, and the mixture was then concentrated with the rotary evaporator and rationed to $1 \mathrm{ml}$ finally. The PAH fraction was analyzed on a Hewlett-
Packard (HP) 6890II GC with a 5973 MSD operated on the scan mode. The separation was carried out on a $30 \mathrm{~m}$ $\times 0.25 \mathrm{~mm}$ i.d.HP-5 (film thickness $0.25 \mu \mathrm{m}$ ) fused-silica capillary column from J\&W Co. The column temperature was initially set at $70^{\circ} \mathrm{C}$ for $6 \mathrm{~s}$, raised to $285^{\circ} \mathrm{C}$ at the speed of $5^{\circ} \mathrm{C} / \mathrm{min}$, and then held at $285^{\circ} \mathrm{C}$ for $12 \mathrm{~min}$. The injection port, interface line, and ion source temperature were maintained at $300^{\circ} \mathrm{C}, 300^{\circ} \mathrm{C}$, and $230^{\circ} \mathrm{C}$, respecttively. Helium with high purity was the carrier gas at a flow of $1.2 \mathrm{ml} / \mathrm{min}$ and a linear velocity of $25.4 \mathrm{~cm} / \mathrm{s}$ at $300^{\circ} \mathrm{C}$. The operation time lasted for up to $73 \mathrm{~min}$. The instrument was calibrated daily with calibration standards and the relative percent difference between the five-point calibration and daily calibration was less than $20 \%$. The procedure was also checked for recovery efficiencies by analyzing street dusts spiked with PAH standards. Procedural blanks, spiked blanks (standards spiked into solvent) and sample duplicates were analyzed routinely. Surrogate standards were added to all the samples (including QA samples) to monitor procedural performance and matrix effects. The average recoveries were between $85 \%-112 \%$.

\subsection{REE Analysis}

$0.1 \mathrm{~g}$ of dried sample (mesh 200) was decomposed in a 
polyterafluoroethylene (PTFE) pressure container by means of a combined $\mathrm{HF} / \mathrm{HClO}_{4}\left(10 \mathrm{~mL} \mathrm{HF}\right.$ and $\left.4 \mathrm{~mL} \mathrm{HClO}_{4}\right)$. After digestion, the samples were evaporated to incipient dryness and redissolved with $\mathrm{HNO}_{3}$ for 2 times. The final sample dissolution was performed with $2 \% \mathrm{HNO}_{3}$. Before analysis, $\mathrm{Ru}$ and Re solutions were added as internal standards to compensate for instrumental drift. Inductively coupled plasma (ICP) mass spectrometry (MS) analysis of the obtained sample solutions was carried out with an externally calibrated Thermo Electron VG PQ EXCELL quadrupole ICP mass spectrometer. Details on the interference corrections applied to correct analytic isotopes for molecular and isobaric interferences are given by Dulski [21]. The analytical procedure was validated by analysis of international reference standards and repeated independent sample preparation. The relative deviations of the standard analyses to the reference values are below $\pm 6 \%$.

\subsection{Data Analysis Techniques}

Isomer ratios of $\mathrm{Flu} /(\mathrm{Flu}+\mathrm{Pyr}) \mathrm{vs} \mathrm{BaA} /(\mathrm{BaA}+\mathrm{Chry})$, and $\mathrm{BaA} /(\mathrm{BaA}+\mathrm{Chry})$ vs $\mathrm{InP} /(\mathrm{InP}+\mathrm{BgP})$ were used to identify the possible sources of PAHs. The principal component analysis (PCA) was conducted to quantify the source contributions of PAHs. The significance level and KMO and Bartlett's test of sphericity were performed to test the adaptability of PCA. The number of significant factors was determined during the stepwise multiple linear regression which identified the factors that significantly improved the regression between the factors and the measured total PAH concentrations [8]. PCA with Varimax rotation was performed using PASW statistics 18 for Windows. The REE patterns of the dust samples are chondrite-normalized concentrations.

\section{Results and Discussion}

\subsection{PAHs Concentrations}

The concentrations of individual PAHs ranged from 10 to $4316 \mathrm{ng} / \mathrm{g}$, the most serious species were phenanthrene, fluorene, benzo[b]fluoranthene, pyrene and chrysene, the maximal values of which were 13,947 ng g-1 at site of X5, followed by 9910 and $9372 \mathrm{ng} / \mathrm{g}$ at site Z2 and C4, respectively. However, acenaphthene, acenaphthylene, anthracene and dibenz[a,h]anthracene had relatively lower concentration in this regions, which was below $200 \mathrm{ng}$ g1 in most cases, while many of which had less than 3ring in their structures. The high molecular weight (HMW) PAHs (4 - 6 rings), ranging from $47.51 \%$ to $82.11 \%$ (mean of $74.79 \%$ ), were the dominant PAH compounds in almost all of the dust samples. The $\Sigma$ PAH16 concentrations ranged from 3515 to $14,470 \mathrm{ng} / \mathrm{g}$ in Changsha, 4190 to $13,197 \mathrm{ng} / \mathrm{g}$ in Zhuzhou and 9530 to $24,488 \mathrm{ng} / \mathrm{g}$ in
Xiangtan and the average concentrations of $\mathrm{P}$ PAH16 were $8760 \mathrm{ng} / \mathrm{g}$ in Chang-Zhu-Tan, $6539 \mathrm{ng} / \mathrm{g}$ in Changsha, $6953 \mathrm{ng} / \mathrm{g}$ in Zhuzhou and 13,527 ng/g in Xiangtan. The highest $\mathrm{PPAH} 16$ concentrations corresponded to Xiangtan sampling site X5 $(24,488 \mathrm{ng} / \mathrm{g})$, then followed by C4 $(14,470 \mathrm{ng} / \mathrm{g}), \mathrm{X} 1(13,337 \mathrm{ng} / \mathrm{g})$ and Z2 $(13,197$ $\mathrm{ng} / \mathrm{g})$. The lowest $\Sigma$ PAH16 concentrations $(3515 \mathrm{ng} / \mathrm{g})$ were observed in site C7, then followed by C8 (3935 $\mathrm{ng} / \mathrm{g}$ ) and $\mathrm{C} 1(4105 \mathrm{ng} / \mathrm{g})$. The PAH concentrations have been compared with results in street dust from other sites reported in literature (Table 2). The $\mathrm{SPAH} 16$ concentrations in this study were higher than those of Shanghai (3180 to 17,090 ng/g, Mean $8480 \mathrm{ng} / \mathrm{g}$ [5]), Beijing (660 to $12,100 \mathrm{ng} / \mathrm{g}$ [9]), Berlin (2400 to $21,000 \mathrm{ng} / \mathrm{g}$, Mean $6400 \mathrm{ng} / \mathrm{g}$ [1]) and USA (Mean $4520 \mathrm{ng} / \mathrm{g}$ Max 15,200 $\mathrm{ng} / \mathrm{g}[22])$. However, they were lower than those of indoor dust of Macao (2720 to 24,830 ng/g, Mean 10,660 ng/g [23]). The sum of seven carcinogenic PAHs (Benz[a]anthracene, Chrysene, Benzo[b]fluoranthene, Benzo[k]fluoranthene, Benzo[a]pyrene, Indeno[1,2,3-cd] pyrene and Dibenz[a,h]anthracene) ranged from 1293 to 11,709 $\mathrm{ng} / \mathrm{g}$, with a mean of $3527 \mathrm{ng} / \mathrm{g}$. Benzo[a]pyrene, which is considered to be the most hazardous of all PAHs (Osborne and Crosby 1987; Cerna et al. 2000; Benford et al. 2010), was detected in all samples analyzed (ranged from 129 to $1827 \mathrm{ng} / \mathrm{g}$, with a mean of $547 \mathrm{ng} / \mathrm{g}$ ) and was more than two times higher in Xiangtan $(971 \mathrm{ng} / \mathrm{g})$ than those in Changsha (309 ng/g) and Zhuzhou (441 ng/g) cities. Compared with the results in street from other sites reported in literature (Table 2), the average concentration of Benzo[a]pyrene in this region $(547 \mathrm{ng} / \mathrm{g})$ was higher than those in USA (260 ng/g, [22]) and Macao (300 ng g-1, [23]), however, it was lower than the concentration of Shanghai (1280 ng/g [5]).

\subsection{PAH Isomer Ratios}

PAH ratios were widely used as directors to detect PAH sources $[5,9,13]$. Some PAH pairs ratios, such as Fluo/ (Flu + Pyr), BaA/(BaA + Chry) and InP/(InP + BgP), had been used as distinct chemical tracers to infer possible sources of PAHs in environmental samples $[8,13]$. For Fluo/(Flu + Pyr), ratios $<0.4,0.4-0.5$ and $>0.5$ suggest petroleum origins, petroleum combustion, and combustion origins of coal, grasses and wood, respectively. For $\mathrm{InP} /(\operatorname{InP}+\mathrm{BgP})$, ratios $<0.2,0.2-0.5$, and $>0.5$ indicated petroleum, petroleum combustion and combustion origins of coal, grasses and wood, respectively [13]. For $\mathrm{BaA} /(\mathrm{BaA}+\mathrm{Chry})$, ratios $<0.2,0.2-0.35$ and $0.35 \mathrm{im}-$ plied petroleum origins, petroleum or combustion (mixed sources), combustion origins of coal, grasses and wood, respectively. In this study, the corresponding cross plots of the ratios of Fluo/(Flu + Pyr), InP/(InP $+\mathrm{BgP})$ and $\mathrm{BaA} /(\mathrm{BaA}+\mathrm{Chry})$ are shown in Figure 1 and Figure 2. 
Table 2. Comparison of PAHs measurements (ng/g) in street dusts from out door collected in different regions in the world.

\begin{tabular}{|c|c|c|c|c|c|c|c|c|c|c|c|c|c|c|c|c|}
\hline & \multicolumn{2}{|c|}{ Chang-Zhu-Tan } & \multicolumn{2}{|c|}{ Changsha } & \multicolumn{2}{|c|}{ Zhuzhou } & \multicolumn{2}{|c|}{ Xiangtan } & \multicolumn{2}{|c|}{ Shanghai } & \multicolumn{2}{|c|}{ Macao } & \multicolumn{2}{|c|}{ Berlin } & \multicolumn{2}{|c|}{ USA } \\
\hline & Mean & Max & Mean & $\operatorname{Max}$ & Mean & Max & Mean & Max & Mean & Max & Mean & Max & Median & $\operatorname{Max}$ & Mean & $\operatorname{Max}$ \\
\hline Nap & 459 & 2212 & 249 & 418 & 375 & 973 & 825 & 2212 & 530 & 1310 & 70 & 140 & 200 & 1900 & 330 & 4300 \\
\hline Acy & 61 & 194 & 51 & 170 & 61 & 194 & 72 & 100 & $\mathrm{Nd}$ & 550 & 50 & 90 & 30 & 100 & 80 & 270 \\
\hline Ace & 45 & 190 & 20 & 38 & 49 & 190 & 74 & 112 & 330 & 580 & 20 & 20 & 50 & 260 & 50 & 180 \\
\hline Flo & 158 & 720 & 100 & 214 & 194 & 720 & 199 & 311 & 390 & 500 & 6 & 150 & 90 & 240 & 120 & 1220 \\
\hline Phe & 1380 & 4316 & 1066 & 1917 & 1468 & 4316 & 1711 & 2260 & 1640 & 3580 & 660 & 1620 & 960 & 2110 & 440 & 2150 \\
\hline Ant & 125 & 534 & 82 & 183 & 137 & 534 & 171 & 270 & 380 & 370 & 120 & 370 & 70 & 210 & 120 & 750 \\
\hline Flu & 1541 & 3831 & 1222 & 2728 & 1234 & 2786 & 2273 & 3831 & 520 & 560 & 1340 & 4240 & 960 & 3190 & 520 & 1890 \\
\hline Pyr & 1026 & 2873 & 737 & 1769 & 845 & 1826 & 1593 & 2873 & 1460 & 2980 & 1960 & 6150 & 670 & 2280 & 430 & 1650 \\
\hline $\mathrm{BaA}$ & 363 & 1411 & 228 & 501 & 200 & 340 & 706 & 1411 & 720 & 1050 & 450 & 1200 & 290 & 1410 & 220 & 690 \\
\hline Chry & 790 & 2146 & 634 & 1443 & 546 & 650 & 1243 & 2146 & 1060 & 1840 & 1920 & 4000 & 550 & 2000 & 390 & 2410 \\
\hline $\mathrm{BbF}$ & 917 & 2881 & 866 & 1578 & 656 & 969 & 1247 & 2881 & 970 & 1440 & 880 & 1880 & 540 & 1900 & \#550 & $\# 1340$ \\
\hline $\mathrm{BkF}$ & 277 & 883 & 217 & 804 & 140 & 220 & 494 & 883 & 830 & 1080 & 390 & 920 & 370 & 1910 & $* 250$ & *610 \\
\hline BaP & 547 & 1827 & 309 & 807 & 441 & 1292 & 971 & 1827 & 1280 & 1920 & 300 & 700 & 290 & 1390 & 260 & 750 \\
\hline InP & 499 & 2013 & 363 & 973 & 291 & 591 & 887 & 2013 & 850 & 280 & 640 & 1510 & 330 & 2110 & 230 & 630 \\
\hline $\mathrm{DbA}$ & 135 & 548 & 96 & 227 & 79 & 148 & 242 & 548 & 540 & 930 & 200 & 520 & 50 & 290 & 230 & 700 \\
\hline $\mathrm{BgP}$ & 438 & 1543 & 299 & 765 & 239 & 466 & 821 & 1543 & 760 & 680 & 1600 & 3200 & 350 & 1280 & 100 & 410 \\
\hline$\Sigma \mathrm{PAH}_{16}$ & 8760 & 24,488 & 6539 & 14,470 & 6953 & 13,197 & 13,527 & 24,488 & 8480 & 17,090 & 10,660 & 26,710 & 论800 & 放22,580 & $\sum 4520$ & 放15,200 \\
\hline
\end{tabular}

Note: \#: Sum of Benzo(b)fluoranthene and Benzo(k)fluoranthene; ": the concentration of Coronene; is: Sum of $\sum$ PAH16 and Benzo(e)fluoranthene and Coronene.

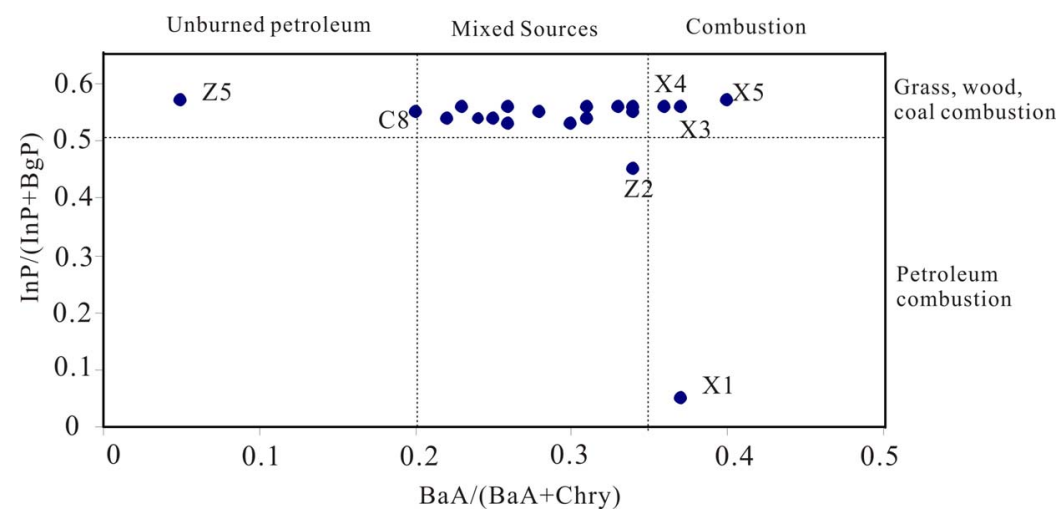

Figure 1. PAH cross plots for the ratio InP/(InP + BgP) vs BaA/(BaA + Chry).

As shown in Figure 1, except for the street dusts at the sites of Z5, C8, X3, X4, X1 and X5, the InP/(InP + BgP) $\mathrm{Vs} \mathrm{BaA} /(\mathrm{BaA}+\mathrm{Chry})$ ratios for all the samples within a relatively narrow range of values indicate a major mixed sources of petroleum and combustion, while Z5 and C8, $\mathrm{X} 3$ and $\mathrm{X} 4$ and $\mathrm{X} 5, \mathrm{X} 1$ indicate a major sources of unburned petroleum, a major combustion of coal, grasses and wood, petroleum combustion, respectively. The results of $\mathrm{InP} /(\mathrm{InP}+\mathrm{BgP}) \mathrm{Vs} \mathrm{BaA} /(\mathrm{BaA}+$ Chry $)$ ratios analysis were confirmed by plotting Fluo/(Flu + Pyr) Vs $\mathrm{BaA} /(\mathrm{BaA}+\mathrm{Chry})$ values except at the site of X1 which indicated a major combustion of coal, grasses and wood source (Figure 2).

\subsection{PCA Analysis}

Principal component analysis (PCA) was performed to separate PAHs having similar sources and modes of input [8]. PCA of the PAHs for Chang-Zhu-Tan dusts resulted in the first two factors $(62.49,23.28$, respectively) accounting for $85.77 \%$ of the total variability (Table 3 ). Factor 1 was heavily weighted by pyrene, benz[a]anthracene, chrysene, benzo[b]fluoranthene, benzo[k]fluoranthene, benzo[a]pyrene, indeno[1,2,3-cd]pyrene, dibenz[a,h]anthracene, and benzo[ghi]perylene. Benz[a]anthra- 


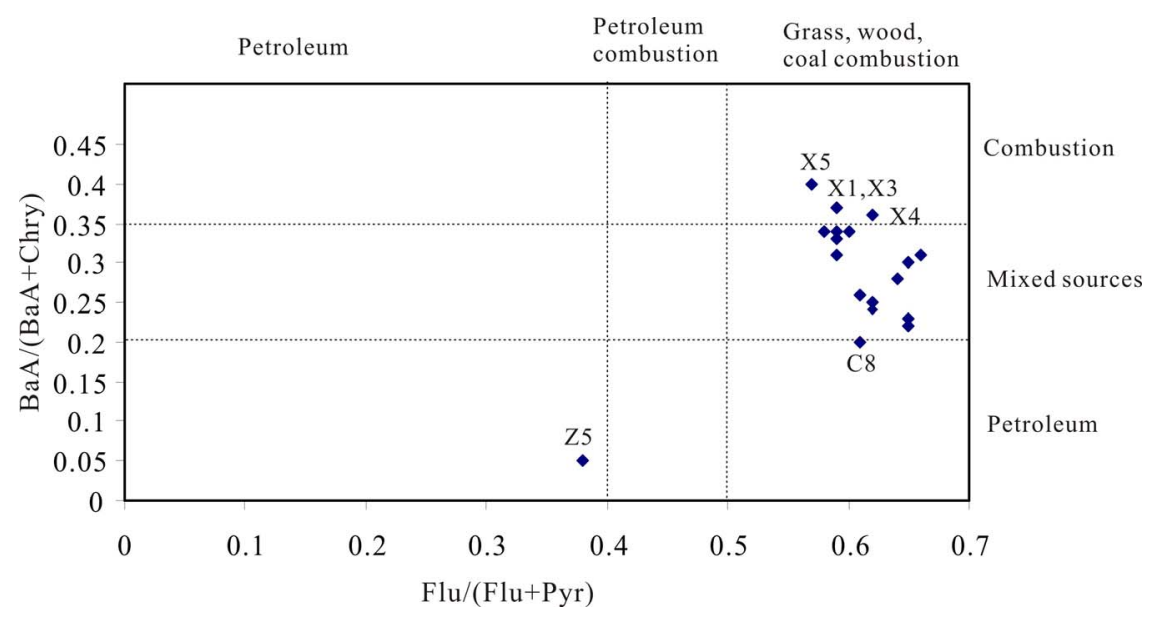

Figure 2. PAH cross plots for the ratio BaA/(BaA + Chry) vs Flu/(Flu + Pyr).

Table 3. Rotated component Matrix of PAHs in street dusts of Chang-Zhu-Tan region.

\begin{tabular}{lccccccccccccccccc}
\hline & Nap & Acy & Ace & Flo & Phe & Ant & Flu & Pyr & BaA & Chry & BbF & BkF & BaP & InP & DbA & BgP & Variance $(\%)$ \\
\hline Factor1 & 0.46 & 0.19 & 0.22 & -0.04 & 0.15 & 0.16 & 0.69 & 0.75 & 0.90 & 0.92 & 0.78 & 0.91 & 0.84 & 0.93 & 0.95 & 0.96 & 62.49 \\
Factor2 & 0.42 & 0.85 & 0.93 & 0.99 & 0.97 & 0.98 & 0.69 & 0.65 & 0.33 & 0.30 & 0.06 & 0.22 & 0.10 & 0.05 & 0.06 & 0.17 & 23.28 \\
\hline
\end{tabular}

cene, chrysene, benzo[k]fluoranthene, benzo[a]pyrene, indeno[1,2,3-cd]pyrene, dibenz[a,h]anthracene, and benzo[ghi]perylene were consistent with the emission characteristics of PAHs from coal combustion and vehicle emission in China [24], while benzo[b]fluoranthene was consistent with the emission of diesel [7] (Simcik et al. 1999).

Factor 2 had a significant positive loading of $2-3$ ring acenaphthylene, acenaphthene, fluorene, phenanthrene, and anthracene (Table 3), which could be considered as combined components of petroleum [7] and coking sources [25]. Table 4 showed that at sites of X5, C4, X6 and $\mathrm{X} 2$ were characterized by higher score of factor 1 as well as at sites of Z2 and X1 were characterized by higher score of Factor 2.

\subsection{REE Distribution}

The concentration of REEs and the chondrite-normalized REE patterns in dust samples, background soils [26] and the three special dust samples from Chang-Zhu-Tan region were presented in Table 5 and Figure 3, respecttively. The content of total rare earth elements ( $\mathrm{REE}$ ) of dust samples varied from 47.3 to $261.09 \mu \mathrm{g} / \mathrm{g}$ which were lower than that of the background soil samples ex- cept for the sample at the site of Z2 $(261.09 \mu \mathrm{g} / \mathrm{g})$ and higher than the values of CWG $(8.11 \mu \mathrm{g} / \mathrm{g})$ and ZYD (65.49 $\mu \mathrm{g} / \mathrm{g})$ except for the sample at the site of C4 $(47.30 \mu \mathrm{g} / \mathrm{g})$. The concentration of the light rare earth elements (LREEs) was higher than that of the heavy rare earth elements (HREEs). The LREE/HREE ratios of the dust samples varied from 3.34 to 10.92 , which were similarly to those of ZYD, ZDD and the background soil samples except for the sample at the site $\mathrm{C} 4$ which was similar to that of CWG. Almost all the samples showed a negative $\mathrm{Ce}$ and $\mathrm{Eu}$ anomaly except samples at the sites of $\mathrm{X} 1$ and $\mathrm{X} 4$, $\mathrm{C}$-soil and ZYD showed positive Ce anomaly and samples at sites of $\mathrm{C} 2, \mathrm{C} 4, \mathrm{Z6}, \mathrm{X} 1, \mathrm{X} 3$ and $\mathrm{X} 4, \mathrm{CWG}$ and ZYD showed positive Eu anomaly.

\subsection{Sources Trace by REE and PCA Analysis}

The sample at site of $\mathrm{C} 4$ showed a negative $\mathrm{Ce}$ and a positive Eu anomaly with a similar chondrite-normalized REE pattern to that of CWG (Figure 3 Changsha) which suggested similar dust sources between the sample at site

Table 4. Factor scores for PAHs in street dusts of Chang-Zhu-Tan region in principal component analysis (PCA).

\begin{tabular}{|c|c|c|c|c|c|c|c|c|c|c|c|c|c|c|c|c|c|c|}
\hline & \multicolumn{8}{|c|}{ Changsha } & \multicolumn{6}{|c|}{ Zhuzhou } & \multicolumn{4}{|c|}{ Xiangtan } \\
\hline & $\mathrm{C} 1$ & $\mathrm{C} 2$ & $\mathrm{C} 3$ & $\mathrm{C} 4$ & $\mathrm{C} 5$ & C6 & $\mathrm{C} 7$ & $\mathrm{C} 8$ & $\mathrm{Z1}$ & $\mathrm{Z} 2$ & $\mathrm{Z} 3$ & $\mathrm{Z} 4$ & $\mathrm{Z} 5$ & Z6 & $\mathrm{X} 1$ & $\mathrm{X} 2$ & $\mathrm{X} 3 \quad \mathrm{X} 4$ & $\mathrm{X} 5 \mathrm{X} 6$ \\
\hline Score of F1 & -0.62 & -0.38 & 0.00 & 1.04 & -0.41 & -0.56 & -0.80 & -0.66 & -0.54 & -1.54 & -0.41 & -0.58 & -0.32 & 0.01 & 0.39 & 0.73 & $0.44 \quad 0.24$ & 3.350 .62 \\
\hline Score of F2 & -0.70 & -0.22 & -0.05 & 0.57 & -0.58 & -0.64 & -0.57 & -0.62 & -0.28 & 3.73 & -0.47 & -0.70 & -0.74 & -0.45 & 0.93 & -0.08 & $0.23-0.07$ & $\begin{array}{ll}0.50 & 0.20\end{array}$ \\
\hline
\end{tabular}


Table 5. Rare earth element contents (g/g) in samples and associated geochemical parameters.

\begin{tabular}{|c|c|c|c|c|c|c|c|c|c|c|c|c|c|c|c|c|c|c|c|c|}
\hline & $\mathrm{La}$ & $\mathrm{Ce}$ & $\operatorname{Pr}$ & $\mathrm{Nd}$ & $\mathrm{Sm}$ & $\mathrm{Eu}$ & $\mathrm{Gd}$ & $\mathrm{Tb}$ & Dy & Но & $\mathrm{Er}$ & $\mathrm{Tm}$ & $\mathrm{Yb}$ & $\mathrm{Lu}$ & ¿LREE & $\Sigma$ HREE & $\Sigma$ REE & $\mathrm{L} / \mathrm{H}$ & $\mathrm{Ce} / \mathrm{Ce}^{*}$ & $\mathrm{Eu} / \mathrm{Eu}^{*}$ \\
\hline $\mathrm{C} 1$ & 27.29 & 5106 & 5.79 & 19.31 & 3.77 & 0.88 & 3.44 & 0.52 & 2.36 & 0.59 & 1.78 & 0.29 & 1.93 & 0.30 & 8.10 & 11.20 & 19.30 & .65 & 0.85 & 0.83 \\
\hline $\mathrm{C} 2$ & 20.77 & 8.05 & 4.51 & 15.29 & 3.06 & 0.94 & 3.04 & 0.44 & 1.97 & 0.50 & 1.45 & 0.24 & 1.56 & 0.24 & 62 & 43 & 2.05 & 8.76 & 0.82 & 1.05 \\
\hline $\mathrm{C} 3$ & 25 & .56 & 5.42 & 18.08 & 3.51 & 0.81 & 2.98 & 0.47 & 2. & 0.54 & 1.59 & 0.27 & 1.73 & 0.27 & 11 & 10.06 & 2.17 & 10.15 & 0.86 & .86 \\
\hline $\mathrm{C} 4$ & 10.50 & 15.00 & 2.44 & 55 & 03 & 0.87 & 2.51 & 0.60 & 2.37 & 0.63 & 1.92 & 0.33 & 2.22 & 0.32 & 5.39 & 10.90 & 7.30 & 3.34 & 0.62 & .31 \\
\hline $\mathrm{C} 5$ & 29.71 & 59.34 & 6.09 & 21.91 & 3 & 0 . & 1 & 9 & 2. & 0.59 & 78 & 0.29 & 5 & 0.30 & 121.82 & 6 & 132.98 & 10.92 & 0.92 & 86 \\
\hline C6 & 22.43 & 43.07 & 4.76 & 17.25 & 3.10 & 0.66 & 2.55 & 0.40 & 2.09 & 0.46 & 1.40 & 0.23 & 1.51 & 0.24 & .27 & 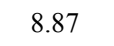 & 100.14 & 10.29 & 0.87 & .80 \\
\hline $\mathrm{C} 7$ & 34.26 & 66.86 & 7.61 & 24.30 & 4.85 & 1.04 & 3.74 & 0.64 & 3.00 & 0.76 & 2.20 & 0.38 & 2.48 & 0.39 & 138.92 & 13.60 & 152.52 & 10.22 & 0.86 & 0.83 \\
\hline C8 & 25.34 & 49.22 & 5.75 & 18.98 & 5 & 0.85 & 3.32 & 0.52 & 2.44 & 0.61 & 3 & 0.31 & 2.06 & 0.32 & 104.00 & 1.40 & 5.40 & 9.12 & 285 & .81 \\
\hline $\mathrm{Z1}$ & 30.67 & 55.37 & 6.79 & 21.76 & 4.45 & 0.90 & 3.63 & 0.63 & 3.04 & 0.76 & 2.22 & 0.38 & 2.43 & 0.37 & 119.94 & 13.43 & 133.37 & 8.93 & 0.80 & 0.77 \\
\hline $\mathrm{Z} 2$ & 57.37 & 105.40 & 13.55 & 44. & 9 & 1. & 7.05 & 1.36 & 7 & 1.76 & 4 & 0.81 & 5 & 0.76 & & 28.81 & 261.09 & 8.06 & 07 & 2 \\
\hline $\mathrm{Z3}$ & 26.35 & 49.25 & 5.92 & 19.49 & 3.96 & 0.86 & 3.50 & 0.56 & 2.75 & 0.68 & 2.06 & 0.34 & 2.29 & 0.35 & 105.82 & 12.52 & 118.34 & 0.40 & 0.02 & 0.79 \\
\hline Z4 & 30.45 & 58.14 & 6.81 & 15.35 & 4. & 0. & 4. & 0.72 & 3. & 0.85 & 2. & 0. & 2.81 & 0.42 & 11 & 15.06 & 131.62 & 7.74 & 0. & 0.72 \\
\hline Z5 & 26.07 & 49.14 & 5.89 & 20.17 & 4.13 & 0.82 & 3.70 & 0.56 & 2.55 & 0.65 & 1.90 & 0.31 & 2.09 & 0.32 & 106.23 & 12.07 & 118.30 & 8.80 & 0.83 & 0.72 \\
\hline Z6 & 29.37 & 49.87 & 6.32 & 19.20 & 4.04 & 1.25 & 3.37 & 0.56 & 2.72 & 0.68 & 2.01 & 0.34 & 2.19 & 0.34 & 11 & 1221 & 122.26 & 9.01 & 0.76 & 1.16 \\
\hline $\mathrm{X} 1$ & 13.30 & 49.31 & 3.33 & 12.38 & 3.87 & 1.23 & 3.49 & 0.56 & 2.42 & 0.67 & 2.03 & 0.34 & 2.28 & 0.35 & 83.41 & 12.14 & 95.55 & 6.87 & 1.54 & 1.14 \\
\hline $\mathrm{X} 2$ & 24.46 & 47.65 & 5.59 & 18.76 & 3. & 0.9 & 3.51 & 0. & 2. & 0.64 & 1.91 & 0.32 & 2.10 & 0.33 & 10 & 1 & 9 & 8.5 & 0.8 & 0.91 \\
\hline $\mathrm{X} 3$ & 26.67 & 52.81 & 5.92 & 13.44 & 4.21 & 1.24 & 3.21 & 0.55 & 2.46 & 0.69 & 2.08 & 0.36 & 2.40 & 0.38 & 104.29 & 12.13 & 116.42 & 8.60 & 0.88 & 1.15 \\
\hline $\mathrm{X} 4$ & 10.35 & 4500 & 2.88 & 046 & 3.02 & 1.12 & 250 & 0.42 & 1.86 & 0.53 & 1.58 & 0.27 & 1.69 & 0.27 & 718 & ט & 81.04 & 7.80 & 1.72 & 1.36 \\
\hline $\mathrm{X} 5$ & 27.42 & 49.33 & 5.76 & 18.81 & 4.05 & 0.96 & 3.16 & 0.55 & 2.53 & 0.64 & 1.88 & 0.32 & 2.10 & 0.33 & 106.33 & 11.52 & 117.84 & 9.23 & 0.82 & 0.91 \\
\hline $\mathrm{X} 6$ & 24.00 & .19 & 5 . & 19.00 & 3.60 & 0 & 3.83 & 0 . & 2. & 0.62 & 1. & 0 & 1. & 0 . & 98.81 & 1 & 3 & 8.15 & 0 . & 0 \\
\hline C- sail & 37.86 & 103.50 & 8.66 & 31.17 & 5.29 & 1. & 5.52 & 0.99 & 5.82 & 1.16 & 3.54 & 0.59 & 3.39 & 0.52 & 187.60 & 21.53 & 209.13 & 8.71 & 1.19 & 0.71 \\
\hline oil & 50.93 & 112.10 & 12.45 & 47.16 & 8.92 & 1.96 & 7.86 & 1.3 & 6.95 & 1.15 & 3.31 & 0.57 & 3.70 & 0.58 & 233.51 & 25.4 & 258 & 9.17 & 0.93 & 0.80 \\
\hline X-soil & 45.56 & 97.71 & 10.74 & 37.99 & 6.87 & 1.53 & 6.34 & 1.02 & 5.65 & 1.29 & 3.36 & 0.55 & 3.57 & 0.58 & 200.40 & 22.35 & 222.75 & 8.97 & 0.92 & 0.79 \\
\hline CWG & 2.33 & 1 & 0 & 0 & 44 & 0 & 0.51 & 0 . & 0. & 0.12 & 0.34 & 0.07 & 0.31 & 0.05 & 6.06 & 2.0 & 8.11 & 2.96 & 0.28 & .76 \\
\hline ZYD & 9.47 & 40.61 & 1.86 & 5.89 & 1.34 & 0.56 & 1.64 & 0.24 & 1.12 & 0.45 & 1.11 & 0.16 & 0.90 & 0.15 & 59.73 & 5.76 & 65.49 & 10.37 & 2.02 & 1.29 \\
\hline ZDD & 27.81 & 53.58 & 6.36 & 21.66 & 4.84 & 0.98 & 4.36 & 0.70 & 3.48 & 0.86 & 2.25 & 0.43 & 2.56 & 0.40 & 115.24 & 15.04 & 130.28 & 7.66 & 0.84 & 0.73 \\
\hline
\end{tabular}

$\mathrm{L} / \mathrm{H}=\mathrm{LREE}(\mathrm{La}-\mathrm{Eu}) / \mathrm{HREE}(\mathrm{Gd}-\mathrm{Lu}) ; \mathrm{Ce} / \mathrm{Ce}^{*}=\mathrm{Cen} /(\mathrm{Lan} \times \mathrm{Prn}) 0.5 ; \mathrm{Eu} / \mathrm{Eu}{ }^{*}=\mathrm{Eun} /(\mathrm{Smn} \times \mathrm{Gdn}) 0.5 ;$ subscripts $\mathrm{n}$ stands for chondrite-normalized value; C-sail, Zsoil and X-soil (Changsha, Zhuzhou and Xiangtan background soil in 2006, respectively): Dai et al. 2008.

of $\mathrm{C} 4$ and CWG (automobile exhaust). However, the REE concentrations at site $\mathrm{C} 4$ were higher than those of CWG which may be attributed to a small proportion of background soil in the dust sample. As shown in Table 1, C4 located in a busy ferry of Xiangiiang River, Changsha, where ships and trucks used diesel as well as cars used petroleum. The PCA analysis also indicated that $\mathrm{C} 4$ has high score of factor 1 which was consistent with the emission characteristics of PAHs from coal combustion and vehicle emission. It could be inferred that the PAHs pollution at the site of $\mathrm{C} 4$ mainly come from traffic emission. The sample from $\mathrm{C} 7$ showed high LREEs enrichment and negative $\mathrm{Ce}$ and $\mathrm{Eu}$ anomaly with a similar chondrite-normalized REE pattern to that of $\mathrm{C}$-soil sample (Figure 3 Changsha). As mentioned before, C7 bearing the lowest total $\mathrm{PAH}$ concentrations in this region was located in an Office area and far away from any factories. It could be inferred that the dust as well as the PAHs pollution at $\mathrm{C} 7$ mainly come from the background soil. The sample from $\mathrm{C} 2$ showed relatively low LREEs enrichment and positive $\mathrm{Eu}$ and negative $\mathrm{Ce}$ anomalies with chondrite-normalized REE pattern between that of ZDD and CWG samples (Figure 3 Changsha), which implied a mixed dust pollution sources. The other samples of Changsha city (from sites of C1, C3, C5, C6 and $\mathrm{C} 8$ ) showed negative $\mathrm{Ce}$ and $\mathrm{Eu}$ anomalies with similar chondrite-normalized REE patterns to that of ZDD sample (Figure 3 Changsha), which suggested that those dusts may have been derived from a similar sources of ZDD as well as the PAHs pollution mainly from coal or coking combustion.

The sample from Z2 showed significant high LREEs 

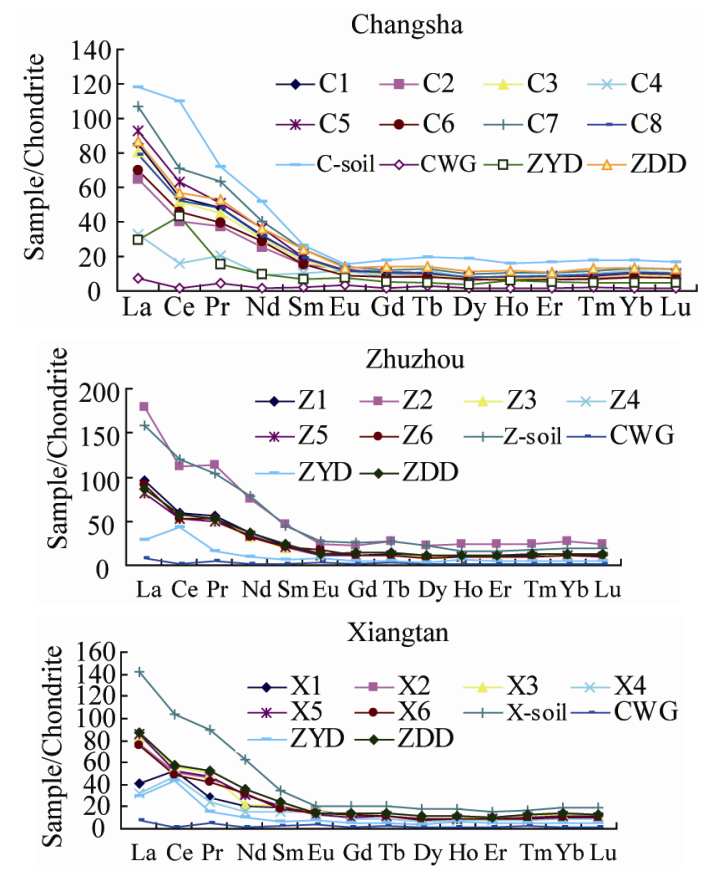

Figure 3. Chondrite-nornalized patterns for Chang-ZhuTan dust and background soil samples. Note: C-soil, REE Values of Changsha background soil in 2006 (Dai et al., 2009); Z-soil REE Values of Zhuzhou background soil in 2006 (Dai et al., 2009); X-soil, REE Values of Xiangtan background soil in 2006 (Dai et al., 2009).

enrichment and characteristic negative $\mathrm{Ce}$ and $\mathrm{Eu}$ anomalies (Figure 3 Zhuzhou), however, its chondrite-normalized REE pattern was different from that of the Z-soil (whose $\mathrm{L} / \mathrm{H}$ was lower than that of Z-soil) and approximately parallel to that of ZDD sample (Figure 3 Zhuzhou), as mentioned before, Z2 located in Zhicheng Chemical plant (Table 1) and characterized by high score of Factor 2 (Table 5) which was attributed to petroleum and coking sources. It could be inferred that the chemical production and coking combustion used in the chemical production should be its major PAH sources. The other samples in Zhuzhou city showed similar chondrite normalized REE patterns to that of ZDD sample (Figure 3 Zhuzhou). Thereby, a good connection between the dust samples at sites of Z1, Z3, Z4, Z5, Z6 and the sample ZDD must be assumed. It would be inferred that the sources of PAHs pollution mainly come from coal or coking combustion.

The samples from $\mathrm{X} 1$ and $\mathrm{X} 4$ showed positive $\mathrm{Ce}$ and $\mathrm{Eu}$ anomalies with similar chondrite-normalized REE patterns to that of the ZYD sample (Figure 3 Xiangtan), which suggested the samples from $\mathrm{X} 1$ and $\mathrm{X} 4$ have been derived from a similar source of ZYD. Table 1 showed that $\mathrm{X} 1$ and $\mathrm{X} 4$ were located in Bantang industrial area and Yuetang industrial area, respectively, and near main highways. PAC analysis also showed high score of factor 2 at site of $\mathrm{X} 1$ and moderate scores of factor 1 at sites of $\mathrm{X} 1$ and X4. It could be inferred that the sources of PAHs pollution at $\mathrm{X} 1$ and $\mathrm{X} 4$ mainly come from industrial production (Smelter and Refinery of Nonferrous Metals production), then from the petroleum emission of vehicles. At the sites of X2, X5 and X6, the samples showed negative $\mathrm{Ce}$ and $\mathrm{Eu}$ anomalies with similar REE patterns to that of the ZDD sample. As Table 1 showed, X5 located in Xiangtan coal-fired power plant and X6 located in an office area but near the Xiangtan coal-fired power plant, while X2 located in a residential area where coal was the main fuel for the residents. The PCA analysis also indicated that at sites of X2, X5 and X6 had high scores of factor 1 . It should be inferred that the dust as well as the PAHs pollution mainly come from coal combustion. The sample from X3 showed negative Ce and positive $\mathrm{Eu}$ anomalies with chondrite-normalized REE patterns between ZDD and ZYD (Figure 3 Xiangtan). As mentioned before, X3 was located in Xiangtan Eastern Bus Station, a traffic area and shopping centre, characterized by moderate high scores of factor 1 and factor 2 (Table 4), which suggested a mixed PAHs pollution sources.

The present study also indicates that the heavy PAHs pollution sites corresponded to the areas where factories, heavy traffic were interweaved, while the light PAHs pollution sites corresponded to the areas where far away from any factories. However, the boundaries among the industry areas, resident area, office areas and traffic areas were not distinct. They always weaved together and almost all of the PAHs in this region had mixing sources, which corresponds to the results of the PAH isomer ratios, PCA and REE analysis as well as the energy structure of this region.

\section{Conclusions}

The PAH levels in dust of Chang-Zhu-Tan urban region were relatively high worldwide. The spatial variation of the PAH concentrations was significantly connected to the distribution of factories which was associated with coal or coking combustion and traffic circulation. Isomer ratios and factor analysis indicated that the main sources of PAHs were the mixing of coal combustion/traffic emissions and coking/petroleum combustion, REE analysis and Factor scores concretely showed the possible dust sources of each sample sites. The major PAHs pollution was coal or coking combustion from all sorts of factories and families, then, followed by traffic exhaust.

The PAHs pollution in dust of Chang-Zhu-Tan urban region should be reduced by means of reducing coal and coking combustion, controlling the number of cars as well as planning residential areas away from the Indus- 
trial and traffic zones.

\section{Acknowledgements}

The authors thank Profession Dr. Xi Zhaozhuang and Dr. Gong Jianhua for collecting the samples. This research was funded by the China Geological Survey for ecosystem geochemistry assessment in cities of Changsha, Zhuzhou and Xiangtan.

\section{REFERENCES}

[1] H. Fromme, T. Lahrz, M. Piloty, H. gebbhardt, A. Oddoy and H. Rüden, "Polycylic Aromatic Hydrocarbons Inside and Outside of Apartments in an Urban Area," Science of the Total Environment, Vol. 326, No. 1-3, 2004, pp. 143149. doi:10.1016/j.scitotenv.2004.02.002

[2] A. Krein, T. Udelhoven, J. N. Audinot, C. Hissler, C. guignard, L. Pfister, H. N. Migeon and L. Hoffmann, "Imaging Chemical Patches on Near-Surface Atmospheric Dust Particles with NanoSIMS 50 to Identify Material Sources," Water Air Soil Pollut, Focus, Vol. 8, No. 5, 2008, pp. 495-803. doi:10.1007/s11267-008-9182-x

[3] W. J. Aalker, R. P. McNutt and C. A. Maslanka, "The Potential of Urban Runoff to Surface Sediments of the Passaic River: Sources and Chemical Characteristics," Chemosphere, Vol. 38, No. 2, 1999, pp. 363-377. doi:10.1016/S0045-6535(98)00186-6

[4] A. S. Mohamed, O. S. Tarek, I. A. E. M. Mohamed, M. I. F. Eiman and E. M. Mohamed, "PAHs in Sediments along the Semi-Closed Areas of Alexandria, Egypt," Journal of Environmental Protection, Vol. 2, 2011, pp. 700709.

[5] Y. Ren, Q. Zhang and J. Chen, "Distribution and Source of Polycyclic Aromatic Hydrocarbons (PAHs) on Dust Collected in Shanghai, People's Republic of China," Bulletin of Environmental Contamination and Toxicology, Vol. 76, No. 3, 2006, pp. 442-449. doi:10.1007/s00128-006-0941-y

[6] A. Gusev, E. Mantseva, Q. Rozovskaya, V. Shatalov, W. Aas and K. Breivik, "Persistent Organic Pollutants in the Environment," EMEP Status Report 3, 2009.

[7] M. F. Simcik, S. J. Eisenreich and P. J. Lioy, "Source Apportionment and Source/Sink Relationships of PAHs in the Coastal Atmosphere of Chicago and Lake Michigan," Atmospheric Environment, Vol. 33, No. 30, 1999, pp. 5071-5078. doi:10.1016/S1352-2310(99)00233-2

[8] C. K. Wang, Y. X. Li, J. L. Liu, L. Xiang, J. H. Shi and Z. F. Yang, "Characteristics of PAHs Adsorbed on Street Dust and the Correlation with Specific Surface area and TOC," Environmental Monitoring and Assessment, Vol. 169, No. 1-4, 2010, pp. 661-670. doi:10.1007/s10661-009-1205-1

[9] L. Xiang, Y. X. Li, Z. F. Yang and N. H. Shi, "Influence of Traffic Conditions on Polycyclic Aromatic Hydrocarbon Abundance in Street Dust," Journal of Environmental Science and Health Part A, Vol. 45, No. 3, 2010, pp. 339-347. doi:10.1080/10934520903467923
[10] N. T. Edwards, "Polycyclic Aromatic Hydrocarbons (PAHs) in the Terrestrial Environment-A Review," Journal of Environmental Quality, Vol. 12, 1983, pp. 427-441. doi:10.2134/jeq1983.00472425001200040001x

[11] N. Yassaa and A. Cecinato, "Composition of Torched Crude Oil Organic Particulate Emitted by Refinery and Its Similarity to Atmospheric Aerosol in the Surrounding Area," Chemosphere, Vol. 60, No. 11, 2005, pp. 16601666. doi:10.1016/j.chemosphere.2005.02.041

[12] C. V. M. Peter, M. Barbaraj and W. Jennifert. "PAHs Underfoot: Contaminated Dust from Coal-Tar Sealcoated Pavement Is Widespread in the United States," Environmental Science \& Technology, Vol. 43, No. 1, 2009, pp. 20-25. doi:10.1021/es802119h

[13] M. B. Yunker, R. W. Macdonald, R. Vingarzan and R. H. Mitchell, "PAHs in the Fraser River Basin, a Critical Appraisal of PAH Ratios as Indicators of PAH Source and Composition," Organic Geochemistry, Vol. 33, No. 4, 2002, pp. 489-515. doi:10.1016/S0146-6380(02)00002-5

[14] Y. T. Shen, K. Y. Wang, S. C. Zhang, Y. B. Ye, Q. Shen and X. J. Huang, "Source Apportionment of Polycyclic Aromatic Hydrocarbons in Surface Soil of Beijing, China," Journal of Agro-Environment Science, Vol. 27, No. 2, 2008, pp. 549-554.

[15] K. H. Johannesson and W. B. Lyons, "The Rare Earth Element Geochemistry of Mono Lake Water and the Importance of Carbonate Complexing," Limnology and Oceanography, Vol. 39, No. 5, 1994, pp. 1141-1154.

doi:10.4319/lo.1994.39.5.1141

[16] P. Gabrielli, C. F. Boutron, A. Marteel, J. R. Petit, B. Delmonte, V. Gaspari, P. Cescon and C. Barbante, "Rare Earth Elements as Tracers of Continental Dust Origin in EPICA Dome C Ice during Glacial and Interglacial Periods," Geophysical Research Abstracts, Vol. 9, 2007, pp. 3374.

[17] Z. F. Tan, G. J. Liu, W. Zhang and Y. Y. Zhou, "Optinum Population Capacity forecast Based on Ecological Footprint Analysis of the Changsha-Zhuzhou-Xiangtan City Cluster," Journal of Wuling, Vol.35, No. 1, 2010, pp. 6669.

[18] B. L. Pan, "Suggest the Ecological Environment of Xiangjiang Drainage Basin Be one of Key Pollution Control Areas in China," Association Central Committee Propaganda Department, August 20, 2010, p. 1.

http://www.mj.org.cn/mjzt/2009lhzt/jyxc/hjzy/200903/t20 090304 33853.htm

[19] J. P. Yin, "Comprehensive Development of the Xiangjiang River and Building with Two Types of Society in Chang-Zhu-Tan Region," Hunan Traffic Technology, Vol. 4, 2010, pp. 103-107.

[20] P. Zhang, Y. M. Shi, Z. W. Zhan, B. S. Hu and Y. W. Hu, "Annual Report on Development of Changsha-ZhuzhouXiangtan City Cluster, Blue Book of Changsha-ZhuzhouXiangtan City Cluster," Social Sciences Academic Press, Beijing, 2010.

[21] P. Dulski, "Reference Materials for Geochemical Studies: New Analytical Data by ICP-MS and Critical Discussion of Reference Values," Geostandards Newsletter, Vol. 25, 
No. 1, 2001, pp. 87-125.

doi:10.1111/j.1751-908X.2001.tb00790.x

[22] J. C. Chuang, G. A. Mack, M. R. Kuhlmann and N. K. Wilson, "Polycyclic Aromatic Hydrocarbons and Their Derivatives in Indoor and Outdoor Air in an Eight-Home Pilot Study," Atmospheric Environment. Part B. Urban Atmosphere, Vol. 25, No. 3, 1991, pp.369-380. doi:10.1016/0957-1272(91)90008-3

[23] S. H. Qi, J. M. Fu, G. Y. Sheng, Z. S. Wang, S. W. Tang, Y. Min, G. Zhang and Y. H. Deng, "Study on Priority Polycyclic Aromatic Hydrocarbons (PAHs) in Dustfall at Macao," Research of Environmental Sciences, Vol. 14, No. 1, 2001, pp. 9-13.

[24] S. C. Zhang, W. Zhang, K. Y. Wang, Y. T. Shen, L. W. $\mathrm{Hu}$ and $\mathrm{X}$. J. Wang, "Concentration, Distribution and
Source Apportionment of Atmospheric Polycyclic Aromatic Hydrocarbons in the Southeast Suburb of Beijing, China," Environmental Monitoring and Assessment, Vol. 151, No. 1-4, 2009, pp. 197-207. doi:10.1007/s10661-008-0261-2

[25] N. R. Khalili, P. A. Scheff and T. M. Holsen, "PAH Source Fingerprints for Coke Ovens, Diesel and Gasoline Engines, Highway Tunnels, and Wood Combustion Emissions," Atmospheric Environment, Vol. 9, No. 4, 1995, pp. 533-542. doi:10.1016/1352-2310(94)00275-P

[26] T. G. Dai, Q. H. Wu, J. Q. Deng and Y. Z. Long, "Assessment of Ecological Geochemistry in Chang-Zhu-Tan Urban Region," Central South University Press, Changsha, 2009, p. 175. 